\title{
CA 125 secretion by peritoneal mesothelial cells
}

\author{
A M Zeillemaker, H A Verbrugh, A A G M Hoynck van Papendrecht, P Leguit
}

\begin{abstract}
Aims-To investigate the secretion of the tumour marker CA 125 by cultured human mesothelial cells; to determine if secretion of CA 125 could be observed by activating the mesothelial monolayers with different cytokines.

Methods-Mesothelial cells were isolated from human omentum and cultured to confluent monolayers on perforated polycarbonate membranes (pore size $0.4 \mu \mathrm{m})$. The mesothelial monolayers were activated and the apical and basolateral secretion of $\mathrm{CA} 125$ compared. To investigate the influence of cytokines, mesothelial cells were cultured and activated with recombinant interleukin$1 \beta$ (rIL-1 $\beta$ ), tumour necrosis factor-a (TNF-a) or lipopolysaccharide from Escherichia coli. The secretion of CA 125 was tested using a microparticle enzyme immunoassay.
\end{abstract}

Results-Mesothelial monolayers secreted CA 125 in a polarised manner with preference for the apical side. Apical polarisation occurred irrespective of the side of the inducing stimulus $(p \leqslant 0.05)$. Non-activated cultured mesothelial monolayers secreted significant quantities of CA 125, indicating constitutive production of this protein. However, CA 125 production was significantly enhanced if mesothelial cells were incubated with rIL-1 $\beta$ ( $p \leqslant 0.05$ ), TNF- $\alpha$ $(p \leqslant 0.05)$, and $E$ coli LPS (p $\leqslant 0.01)$.

Conclusions-Human mesothelial monolayers secrete CA 125 preferentially from their apical surfaces. The secretion of CA 125 can be enhanced by the inflammatory cytokines $\mathrm{I}-1 \beta$, TNF- $a$, and by $E$ coli LPS.

Department of

Surgery, Diakonessen

Hospital, Utrecht, The

Netherlands

A M Zeillemaker

A A G M Hoynck van

Papendrecht

$P$ Leguit

Department of

Medical Microbiology,

Diakonessen Hospital,

Utrecht

H A Verbrugh

Correspondence to:

A M Zeillemaker,

Department of Surgery,

Diakonessen Hospital,

Bosboomstraat 1, 3582 KE

Utrecht, The Netherlands.

Accepted for publication

7 September 1993

\section{(F Clin Pathol 1994;47:263-265)}

Cancer antigen 125 (CA 125) is a 220000 molecular weight glycoprotein defined by a murine monoclonal antibody OC 125 , which was raised against the serous ovarian carcinoma cell line OVCA $433 .{ }^{1}$ Immunohistochemical studies have shown that CA 125 is expressed by coelomic epithelium during embryonic development and by most ovarian epithelial tumours. CA 125 was detected in the serum samples of about $80 \%$ of patients with ovarian cancer. ${ }^{2}$ Subsequently, CA 125 was a clinically useful tumour marker in the follow up of patients treated for ovarian adenocarcinomas. ${ }^{34}$
However, CA 125 proved not to be a tumour specific antigen, as its presence was shown in the normal epithelium of the female genital tract; in gastric and colonic mucosal cells; and at the luminal surface of mesothelium lining the peritoneum, pleura, and pericardium. ${ }^{5}$

High concentrations of CA 125 have been found in the sera of patients after abdominal surgery and in patients during episodes of bacterial peritonitis. These findings suggest that mesothelial cells are active in CA 125 synthesis and secretion..$^{6-8}$

We investigated the CA 125 secretion of human mesothelial cells in an in vitro model of peritonitis. The study focused on the secretion pattern of CA 125 by an MC monolayer and the enhancement of MC CA 125 secretion by several inflammatory stimuli.

\section{Methods}

Mesothelial cells were isolated from human omentum, according to modified techniques from Nicolson and Wu. ${ }^{9}{ }^{10}$ Small pieces of omentum were removed early in the operative procedure from patients undergoing abdominal surgery for non-infectious conditions. All patients gave informed consent. After removal, the pieces of omentum were placed in medium M199 (Gibco, Life Technologies, Paisley, Scotland) at $37^{\circ} \mathrm{C}$. Within two hours the pieces of omentum were transferred to phosphate buffered saline (PBS) containing $0.05 \%$ trypsin-0.02\% EDTA (Gibco). After 15 minutes' incubation at $37^{\circ} \mathrm{C}$ under gentle shaking, the detached mesothelial cells were pelleted by centrifugation at $1200 \mathrm{rpm}$ for five minutes. The pelleted cells (mesothelial cells with other cells, predominantly erythrocytes) were resuspended in M199 supplemented with fetal bovine serum (FBS; Gibco), gentamicin (10 $\mu \mathrm{g} / \mathrm{ml}$; Merck, Darmstadt, Germany), vancomycin $(25 \mu \mathrm{g} / \mathrm{ml}$; Gibco), and glutamine ( $2 \mathrm{mM})$. The cells were grown until confluence in a $37^{\circ} \mathrm{C}$, fully humidified, $5 \% \mathrm{CO}_{2}$ cabinet in polystyrene culture flasks $\left(75 \mathrm{~cm}^{2}\right.$, Costar, Cambridge, Massachusetts, USA) precoated with fibronectin. Mesothelial cells were identified by immunofluorescence staining using mouse monoclonal antibodies against the cytokeratins 6 and $18 .^{11}$

To investigate the apical and basolateral secretion of CA-125, mesothelial cells were subcultured to confluent monolayers on polycarbonate membranes $(0.4 \mu \mathrm{m}$ pore size, $24.5 \mathrm{~mm}$ diameter) of Transwell cell culture 


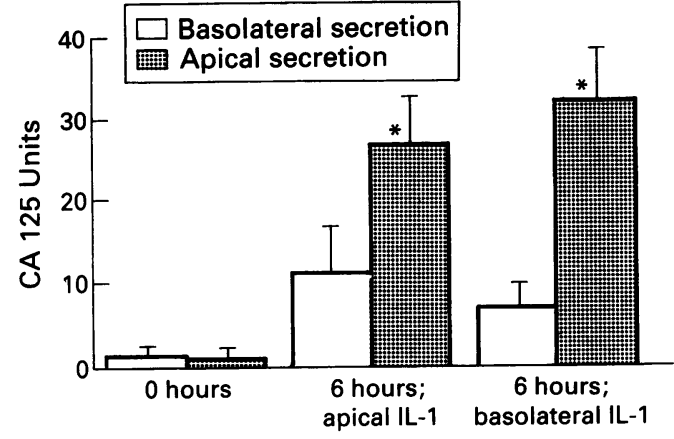

Figure 1 Apical and basolateral secretion of CA 125 by confluent monolayers of mesothelial cells. Stimulation of the mesothelial cells took place by adding $r I L-1 \beta$

(25 U/ml) at 0 hours to the apical or basolateral side of the monolayer. Results are expressed as the mean (SEM) in units of five separate experiments. ${ }^{*}$ Apical secretion was significantly higher compared with the basolateral secretion of $C A 125$ at the same timepoint $(p \leqslant 0.05$, two tailed paired Student's $t$ test).

chamber inserts (Costar). The filters were precoated with fibronectin before mesothelial cells were added. Mesothelial cell monolayers reached confluence in five days as determined by May-Grünwald-Giemsa staining. Pretreatment of the monolayer with human recombinant interleukin-1 $\beta$ (rIl-1 $\beta$; $25 \mathrm{U} / \mathrm{ml}$; Genzyme Corporation, Boston, Massachusetts, USA) did not influence the microscopic morphology of the confluent monolayer. In all experiments culture medium without antibiotics was used. Medium was refreshed before adding $\mathrm{rIl}-1 \beta$ to either the upper or lower compartment of the Transwell system. At nought and six hours, samples from both compartments were taken and stored at $-70^{\circ} \mathrm{C}$ until tested for CA 125 .

To find out whether other stimuli besides rIl-1 $\beta$ were able to induce the mesothelial cells to secrete CA 125 , these were subcultured to confluent monolayers in six well culture dishes (Costar). The wells were incubated with tumour necrosis factor- $a$ (TNF- $a$; $100 \mathrm{U} / \mathrm{ml}$; Genzyme Corporation), lipopolysaccharide from Escherichia coli (LPS; $1 \mu \mathrm{g} / \mathrm{ml}$;

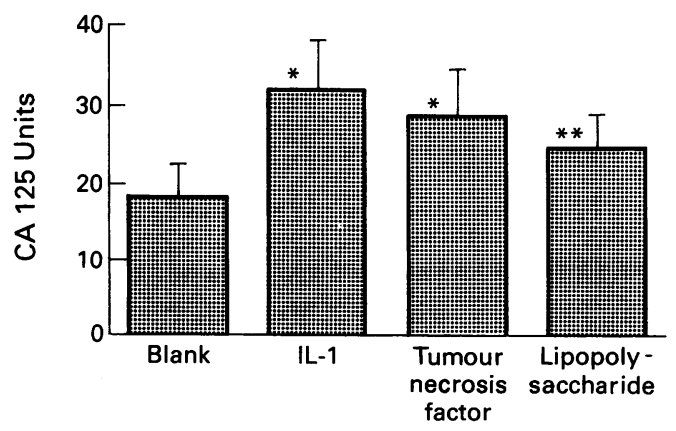

Figure 2 Influence of inflammatory stimuli on apical $C A 125$ secretion of mesothelial cells. Stimulation of the mesothelial cells took place by adding $r I L-1 \beta(25 \mathrm{U} / \mathrm{ml})$, TNF-a (100 U/ml), or LPS E coli $(1 \mu \mathrm{g} / \mathrm{ml})$ at 0 hours. $C A 125$ secretion was measured six hours later. Results are expressed as the mean (SEM) units $C A 125$ based on four separate experiments. ${ }^{\star} C A 125$ secretion was significantly higher compared with the secretion of unstimulated mesothelial cells at 6 hours $\left({ }^{\star} p \leqslant 0.05\right.$ ${ }_{\star \star} p \leqslant 0 \cdot 01$; two tailed paired Student's $t$ test).
Sigma Chemical Co, St Louis, Missouri, USA); or $\mathrm{rIl}-1 \beta$ (25 U/ml). A well without a stimulus was used as control. Six hours after incubation, samples of the supernatant fluids were taken and stored at $-70^{\circ} \mathrm{C}$ until tested for CA 125.

A microparticle enzyme immunoassay (MEIA) was used (IMx CA 125, Abbott Laboratories, Abbott Park, Illinois, USA) for the quantitative measurement of secreted human CA 125 by the mesothelial cell monolayers.

\section{Results}

Activated mesothelial cell monolayers noticeably show a polarity in secretion of CA 125 in favour of the apical side of the monolayer. Whether the stimulus is introduced to the apical or basolateral side of the mesothelial cell monolayer seems to be of no importance, as both modes of stimulation lead to preferential secretion of CA 125 towards the apical side of the monolayer (fig 1 ).

For six hours, mean (SD) $17 \cdot 9(4 \cdot 1)$ units of CA 125 were secreted by cultured human mesothelial cells without deliberate activation of the cells with inflammatory stimuli. All stimuli used for the mesothelial cell monolayers induced a noticeable increase in the secretion of CA 125 into the supernatant fluid. The most effective stimulus of mesothelial cell CA 125 secretion was seen with rIL-1 $\beta$; a $77 \%$ increase was noted when $\mathrm{rIL}-1 \beta$ was present in the incubation mixture (fig 2 ).

\section{Discussion}

CA 125 is a highly sensitive tumour marker for ovarian epithelial tumours; OC 125, the antibody against CA 125, can recognise all of six human ovarian cancer cell lines. ${ }^{1}$ In spite of the fact that OC 125 fails to react with normal ovary cell lines, and with 13 out of 14 non-ovarian cancer cell lines, the specificity of CA 125 is remarkably low. Increased concentrations of serum CA 125 have been found in patients with liver cirrhosis, hepatocellular carcinoma, and tuberculous peritonitis. ${ }^{7812}$ Increased serum CA 125 concentrations are also seen after abdominal surgery. ${ }^{6}$ Increased serum CA 125 concentrations have likewise been detected in women during the menstrual cycle, pregnancy, and in pelvic inflammatory disease. ${ }^{13} 14$ The results of the present study suggest that increased serum CA 125 concentrations in all the cases mentioned may have their origin in activated peritoneal mesothelium.

Mesothelium has sophisticated junctional complexes that might allow a gradient of $\mathrm{CA}$ 125 to be created. ${ }^{15}$ Other workers have stated that the peritoneum serves as a barrier for high molecular weight tumour antigens such as CA 125, as CA 125 values in the ascites of patients with ovarian carcinoma were found to be up to 130 times higher compared with those in the serum. ${ }^{16}{ }^{17}$ In our in vitro model the apical side of the mesothelial cell monolayer correlates with the side facing 
the abdominal cavity in vivo. Our results indicate that CA 125 is preferentially secreted towards the abdominal cavity.

These results further support the concept that peritoneum indeed forms a barrier for CA 125 transport and contributes actively to the CA 125 gradient across the peritoneal membrane. It is likely that CA 125 reaches the circulation through lymphatic absorption via the large fenestrae present in the diaphragmatic peritoneum.

Polarised secretion of proteins by a cultured monolayer of mesothelial cells is not unique to CA 125: IL-8, a chemoattractant for neutrophils, ${ }^{18}$ is also produced by mesothelial cells and is likewise secreted preferentially via the apical surface of activated mesothelial cells. This gradient of IL-8 is probably of paramount importance in the migration of neutrophils through the mesothelial cell monolayer towards the peritoneal cavity. ${ }^{19}$

The active role of mesothelium in inflammatory processes during bacterial and nonbacterial (carcinomatous) peritonitis is not yet fully understood. However, the present data show that CA 125 can no longer be seen only as a tumour marker. Further investigations are recommended to delineate the role of CA 125 production by mesothelial cells.

We thank Lène Biermans for technical assistance and Peter $\mathrm{Kr}$ von dem Borne for statistical analysis. This study was supported by the Dutch Kidney Foundation grant No supported.

1 Bast RC Jr, Feeney M, Lazarus H, Nadler LM, Colvin RB, Knapp BC. Reactivity of a monoclonal antibody with human ovarian carcinoma. $\mathcal{f}$ Clin Invest 1981; 68:1331-7.

2 Bast RC Jr, Klug TL, John ES, et al. A radioimmunoassay using a monoclonal antibody to monitor the course of epithelial ovarian cancer. $N$ Engl $\mathcal{f}$ Med 1983;309: 883-7.
3 Canney PA, Moore M, Wilkinson PM, James RD. Ovarian cancer antigen CA 125: a prospective clinical assessment of its role as a tumormarker. $\mathrm{Br} \mathcal{f}$ Cancer 1984;50:765-9.

4 Einhorn N, Bast RC Jr, Knapp RC, Tjernberg B, Zurawski VR. Preoperative evaluation of serum CA 125 levels in patients with primary epithelial ovarian cancer. Obstet Gynecol 1986;67:414-16.

5 Kabawat SE, Bast RC Jr, Bhan AK, et al. Tissue distribution of a coelomic epithelium related antigen recognized by the monoclonal antibody OC 125 . Int $\mathcal{f}$ Gynecol by the monocl

6 Talbot RW, Jacobsen DJ, Nagorney DM, Malkasian GD, Ritts RE Jr. Temporary elevation of CA 125 after abdominal surgical treatment for benign disease and cancer. Surg Gynecol Obstet 1989;168:407-12.

7 Molina R, Filella X, Bruix J, et al. Cancer antigen 125 in serum and ascitic fluid of patients with liver diseases. Clin Chem 1991;37:1379-83.

8 Okazaki K, Mizuno K, Katoh K, Hashimoto S, Fukuchi S. Tuberculous peritonitis with extraordinarily high serum CA 125. ₹ Med 1992;23:353-61.

9 Nicholson LJ, Clarke JMF, Pittilo RM, Machin SJ, Woolf N. The mesothelial cell as a nonthrombotic surface. N. The mesothelial cell as a non
Thromb Haemostas 1984;37:108-12.

$10 \mathrm{Wu}$ YJ, Parker LM, Binder NE, et al. The mesothelial keratins; A new family of cytoskeletal proteins identified in cultured mesothelial cells and nonkeratizing epithelia. Cell 1982;31:693-703.

11 Connell ND, Rheinwald JG. Regulation of the cytoskeleton in mesothelial cells: Reversible loss of keratin and increase in vimentin during rapid growth in culture. Cell 1983;34:245-53.

12 Bergmann JF, Bidart JM, George $M$, Beaugrand M, Levy VG, Bohuon C. Elevation of CA 125 in patients with benign and malignant ascites. Cancer 1987;59:213-17.

13 Lehtovirta P, Apter D, Stenman U-H. Serum CA 125 levels during the menstrual cycle. Br $\mathcal{F}$ Obstet Gynecol
lovirta $P$, Apter D, Stenman U-H. Serum CA 125
. 1990;97:930-3.

14 Halila H, Stenman U-H, Seppälä M. Ovarian cancer antigen CA 125 levels in pelvic inflammatory disease and pregnancy. Cancer 1986;57:1327-9.

15 Dobbie JW. New concepts in molecular biology and ultrastructural pathology of the peritoneum: their significance for peritoneal dialysis. Am $\mathcal{F}$ Kidney Dis 1990; 15:97-109.

16 Hunter VJ, Weinberg JB, Haney AF, et al. CA 125 in peritoneal fluid and serum from patients with benign gynecologic conditions and ovarian cancer. Gynecol Oncol 1990;36:161-5.

17 Fleuren GJ, Nap M, Aalders JG, Baptist Trimbos J, de Bruijn HWA. Explanation of the limited correlation between tumor CA 125 content and serum CA 125 between tumor CA 125 content and serum CA 125 antigen levels in pat

18 Baggiolini M, Walz A, Kunkel SL. Neutrophil-activating peptide-1/interleukin 8 , a novel cytokine that activates neutrophils. F Clin Invest 1989;84:1045-9.

19 Zeillemaker AM, Hoynck van Papendrecht AAGM, Roos D, Verbrugh HA, Leguit P. Neutrophil adherence to and migration through human mesothelial cell monolayers. Eur Surg Res 1993;25:118. 